\title{
Design and Synthesis of Orally Bioavailable 4-Methyl Heteroaryldihydropyrimidine Based Hepatitis B Virus (HBV)
}

\section{Capsid Inhibitors}

Zongxing Qiu, Xianfeng Lin, Mingwei Zhou, Yongfu Liu, Wei Zhu, Wenming Chen, Weixing Zhang, Lei Guo, Haixia Liu, Guolong Wu, Mengwei Huang, Min Jiang, Zhiheng Xu, Zheng Zhou, Ning Qin, Shuang Ren, Hongxia Qiu, Sheng Zhong, Yuxia Zhang, Yi Zhang, Xiaoyue Wu, Liping Shi, Lina Zhu, Fang Shen, Yi Mao, Xue Zhou, Wengang Yang, Jim Z. Wu, Guang Yang, Alexander V. Mayweg, Hong C. Shen, Guozhi Tang

\section{Supporting Information}

\section{Contents}

General Experimental Conditions Used in Synthesis and Purification of Key Intermediates.

X-ray Single Crystal Structure of $(S)-7 \mathbf{a}$.

${ }^{1}$ H-NMR Spectrum of $\mathbf{3 4 a}$.

Data Collection and Refinement Statistics of Y132A-34a Co-crystal Structure.

The Binding Site of 34a at the A-B Spike.

CYP Inhibition and Plasma Protein Binding Tests of 34a.

Size-Exclusion Chromatography (SEC) Study of Capsid Assembly.

Electron Microscopy Study of Capsid Aggregation Induced by 34a.

\section{General Experimental Conditions Used in Synthesis and Purification}

All of the starting materials were obtained commercially and were used without further purification. All of the reported yields are for isolated products and are not optimized. All of the reactions involving air-sensitive reagents were performed under argon atmosphere. The intermediates 
were purified by flash chromatography using one of the following instruments: i) Biotage SP1 system and the Quad 12/25 cartridge module. ii) ISCO CombiFlash chromatography instrument. Silica gel brand and pore size: i) KP-SIL $60 \AA$, particle size: $40-60 \mu \mathrm{M}$; ii) CAS registry NO: silica gel: 6323167-4, particle size: 47-60 $\mu \mathrm{M}$; iii) ZCX from Qingdao Haiyang Chemical Co., Ltd, pore size: 200-300 or 300-400 mesh. LC-MS spectra were obtained using a MicroMass Platform LC (Waters Alliance 2795-ZQ2000). ${ }^{1} \mathrm{H}$ NMR spectra were obtained using a Bruker Avance $400 \mathrm{MHz}$ NMR spectrometer.

Synthesis of Amidines 12. Generally, amindines 12 were prepared by two different methods, as represented by the synthesis of thiazole-2-carboxamidine II shown below.

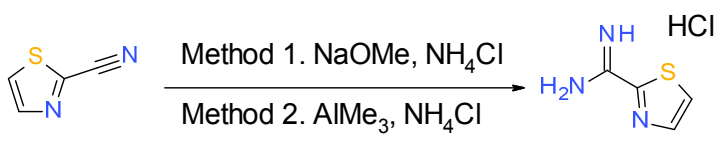

I II

Method 1: To a stirring solution of thiazole-2-carbonitrile $\mathbf{I}(1.5 \mathrm{~g}, 14 \mathrm{mmol})$ in $5 \mathrm{~mL}$ of dry $\mathrm{MeOH}$ was added dropwise a solution of sodium methoxide $(0.74 \mathrm{~g}, 14 \mathrm{mmol})$ in $10 \mathrm{~mL}$ of dry methanol. The reaction mixture was stirred at $\mathrm{rt}$ until the reaction was complete. $\mathrm{NH}_{4} \mathrm{Cl}(1.5 \mathrm{~g}, 28$ mmol) was added into the flask in one portion and the reaction mixture was stirred overnight. The undissolved material was removed by filtration and the filtrate was concentrated to afford thiazole-2carboxamidine hydrochloride II as grey solid that was used directly in the subsequent step without further purification.

Method 2: To a stirred suspension of $\mathrm{NH}_{4} \mathrm{Cl}$ in toluene $(400 \mathrm{~mL})$ was added $\mathrm{Al}\left(\mathrm{CH}_{3}\right)_{3}$ solution $(1.0 \mathrm{M}, 56 \mathrm{~mL})$ dropwise (over $30 \mathrm{~min}$ ) at $0{ }^{\circ} \mathrm{C}$. After the mixture was stirred at $\mathrm{rt}$ for $30 \mathrm{~min}$, a solution of thiazole-2-carbonitrile $\mathbf{I}(5.24 \mathrm{~g}, 47.6 \mathrm{mmol})$ in toluene $(10 \mathrm{~mL})$ was added into the flask and the reaction mixture was stirred at $80^{\circ} \mathrm{C}$ for $16 \mathrm{~h}$. After cooled to rt, the mixture was poured into a slurry of silica gel in DCM. After stirring for 20 min, the slurry was filtered and washed with $\mathrm{MeOH}$ 
three times and concentrated in vacuum to afford thiazole-2-carboxamidine II. MS: calc'd $\left(\mathrm{MH}^{+}\right)$ 128.2, $\exp \left(\mathrm{MH}^{+}\right)$128.1.

Synthesis of $(\boldsymbol{S})$-4,4-Difluoroproline Methyl Ester V. Amino ester V was prepared by the method shown below.

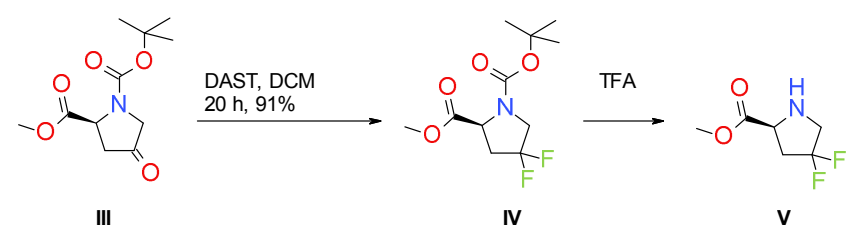

To a solution of III (1.0 g, $3.5 \mathrm{mmol})$ in anhydrous DCM $(15 \mathrm{~mL})$ was added diethylaminosulfur trifluoride (DAST) $(1.4 \mathrm{~g}, 1.2 \mathrm{~mL}, 8.7 \mathrm{mmol})$ at $0{ }^{\circ} \mathrm{C}$. The resultant mixture was stirred at $\mathrm{rt}$ for $20 \mathrm{~h}$, before it was poured onto ice and extracted with EtOAc. The organic layer was washed with saturated $\mathrm{NaHCO}_{3}$ solution and brine, dried over anhydrous $\mathrm{Na}_{2} \mathrm{SO}_{4}$, and concentrated in vacuum to give $\mathbf{I V}$ as yellow oil $(0.85 \mathrm{~g})$.

To a solution of IV $(0.85 \mathrm{~g}, 3.2 \mathrm{mmol})$ in DCM $(5 \mathrm{~mL})$ was added TFA $(2 \mathrm{~mL})$, and the mixture was stirred at $\mathrm{rt}$ for $4 \mathrm{~h}$. After removal of the solvent and excess TFA in vacuum, the TFA salt of methyl (2S)-4,4-difluoropyrrolidine-2-carboxylate $\mathbf{V}$ was obtained as pale solid (0.90 g).

Synthesis of tert-Butyl Ester 20. The tert-butyl ester $\mathbf{2 0}$ was prepared by following the procedures shown below.

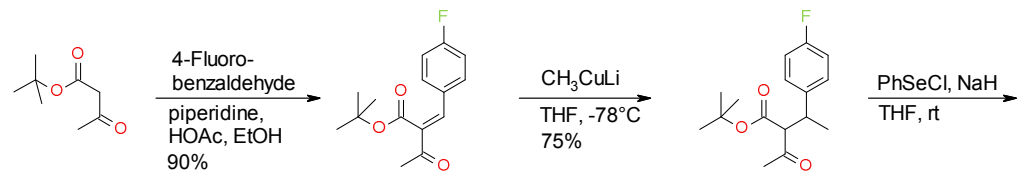

19

VI

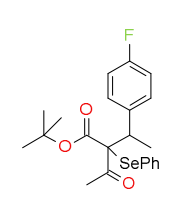

VIII

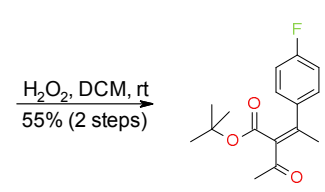

IX

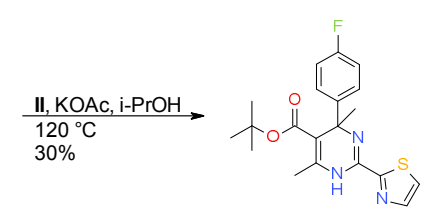

20 
A mixture of 4-fluorobenzaldehyde (12.4 g , $0.1 \mathrm{~mol}), 3$-oxo-butyric acid tert-butyl ester (15.8 $\mathrm{g}, 0.1 \mathrm{~mol})$, piperdine $(0.43 \mathrm{~g}, 5 \mathrm{mmol})$ and $\mathrm{AcOH}(0.3 \mathrm{~g}, 5 \mathrm{mmol})$ in anhydrous ethanol $(200 \mathrm{~mL})$ was stirred at $\mathrm{rt}$ for $12 \mathrm{~h}$. After removal of the solvent, the residue was purified by flash chromatography (EtOAc : hexane $=1: 10)$ to afford 2-[1-(4-fluoro-phenyl)-meth-ylidene]-3-oxobutyric acid tert-butyl ester VI as yellow solid (23.8 g, 90\% yield). MS: calc'd (MH $\left.{ }^{+}\right)$265.1, exp $\left(\mathrm{MH}^{+}\right) 265.1$.

To a suspension of copper(I) iodide $(1.81 \mathrm{~g}, 9.5 \mathrm{mmol})$ in $20 \mathrm{~mL}$ of anhydrous THF was added a solution of methylithium $(1.6 \mathrm{M}$ in ether, $6.0 \mathrm{~mL}, 9.5 \mathrm{mmol})$ under argon at $0{ }^{\circ} \mathrm{C}$ and the mixture was stirred at $0{ }^{\circ} \mathrm{C}$ for $1 \mathrm{~h}$. A solution of VI $(8.0 \mathrm{~g}, 31.2 \mathrm{mmol})$ in $50 \mathrm{~mL}$ of anhydrous THF was added dropwise into the flask and the mixture was stirred at $-78^{\circ} \mathrm{C}$ for $1 \mathrm{~h}$. The reaction mixture was quenched with saturated $\mathrm{NH}_{4} \mathrm{Cl}$ solution and extracted with EtOAc. The organic layer was washed with brine, dried over anhydrous $\mathrm{Na}_{2} \mathrm{SO}_{4}$, and concentrated. The residue was purified by flash column chromatography $($ EtOAc : hexane $=1: 10)$ to afford 2-[1-(4-fluoro-phenyl)-ethyl]-3-oxo-butyric acid tert-butyl ester VII as oil (0.8 g, 75\% yield). MS: calc'd (M-H) 279.1, exp (M-1-H) 279.2.

To a solution of VII $(0.2 \mathrm{~g})$ in anhydrous THF $(3 \mathrm{~mL})$ was added $\mathrm{NaH}(60 \%, 43.2 \mathrm{mg}, 1.08$ mmol) in several portions under argon. After the mixture was stirred at $\mathrm{rt}$ for $5 \mathrm{~min}$, phenylselenyl chloride $(0.21 \mathrm{~g}, 1.08 \mathrm{mmol})$ in THF $(1 \mathrm{~mL})$ was added into the flask. After $1 \mathrm{~h}$ stirring, the mixture was treated with pentene/ether $(6 \mathrm{~mL}, \mathrm{v} / \mathrm{v}=1 / 1)$ and saturated $\mathrm{NaHCO}_{3}$ solution $(3 \mathrm{~mL})$. The organic layer was washed with brine and then treated with $\mathrm{H}_{2} \mathrm{O}_{2}$ solution $(30 \%, 0.2 \mathrm{~mL})$ in DCM $(5 \mathrm{~mL})$. The mixture was stirred at $\mathrm{rt}$ for $0.5-2 \mathrm{~h}$ until the reaction was complete. It was diluted with DCM (10 $\mathrm{mL}$ ) and the organic layer was washed with saturated $\mathrm{NaHCO}_{3}$ solution, sodium sulfite, water and brine. Then the organic layer was dried over anhydrous $\mathrm{Na}_{2} \mathrm{SO}_{4}$. After removal of the solvent, the residue was purified by flash chromatography (EtOAc : hexane $=1: 10)$ to afford 2-acetyl-3-(4-fluorophenyl)-but-2-enoic acid tert-butyl ester IX as yellow oil ( $0.11 \mathrm{~g}, 55 \%$ yield over 2 steps). MS: calc'd $\left(\mathrm{MH}^{+}\right)$279.1, $\exp \left(\mathrm{MH}^{+}\right)$279.2. 
A mixture of IX (0.56 g, $2.0 \mathrm{mmol})$, thiazole-2-carboxamidine hydrochloride II $(0.33 \mathrm{~g}, 2.0$ $\mathrm{mmol})$ and $\mathrm{KOAc}(200 \mathrm{mg}, 2.0 \mathrm{mmol})$ in isopropanol $(5 \mathrm{~mL})$ was stirred at $120{ }^{\circ} \mathrm{C}$ for $3 \mathrm{~h}$. After removal of the solvent, the residue was purified by flash chromatography (EtOAc : hexane $=1: 9$ ) to afford 4-(4-fluoro-phenyl)-4,6-dimethyl-2-thiazol-2-yl-1,4-dihydro-pyrimidine-5-carboxylic acid tertbutyl ester 20 as yellow solid (233 mg, 30\% yield). MS: calc'd $\left(\mathrm{MH}^{+}\right) 388.1$, exp $\left(\mathrm{MH}^{+}\right) 388.1$.

\section{X-ray Structure of $(S)-7$ a}

The absolute stereochemistry of (S)-7a was confirmed by a single crystal X-ray study.
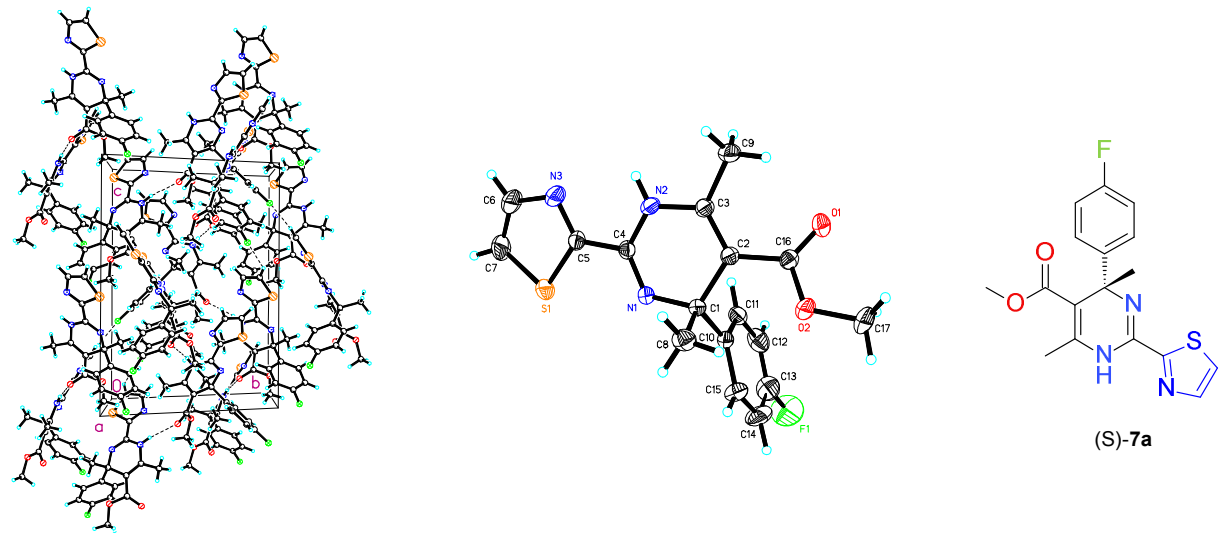

(S)-7a

Figure S1. X-ray crystal structure of $(S)$-7a.

\section{${ }^{1}$ H NMR Spectrum of $34 a$.}

(2S)-4,4-Difluoro-1-[[(4S)-4-(4-fluorophenyl)-5-methoxycarbonyl-4-methyl-2-thiazol-2-yl-1Hpyrimidin-6-yl]methyl]pyrrolidine-2-carboxylic acid (34a).

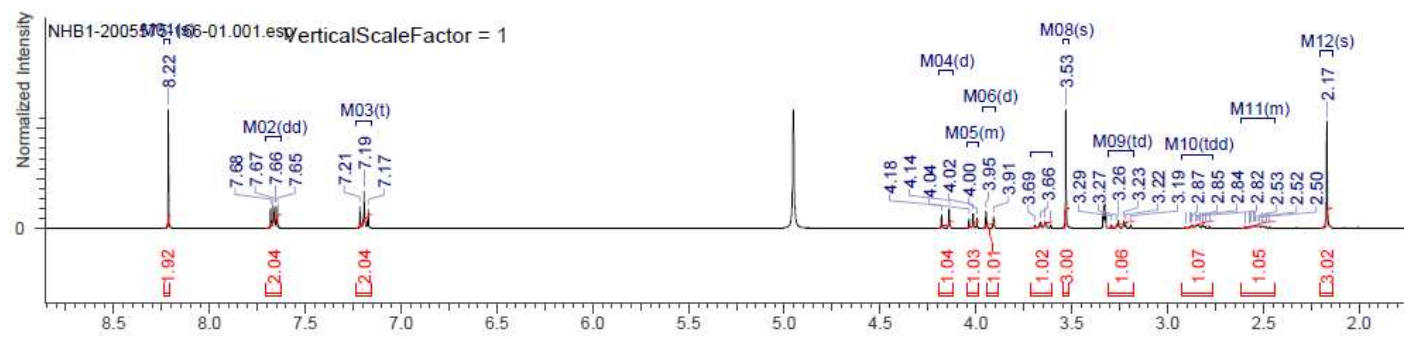


Figure S2. ${ }^{1}$ H-NMR spectrum of compound 34a.

\section{Data Collection and Refinement Statistics of Y132A-34a Co-crystal Structure}

Table S1. Data collection and refinement statistics

\begin{tabular}{|c|c|}
\hline & Y132A hexamer-8338 \\
\hline Wavelength $(\AA ̊)$ & 0.9793 \\
\hline Resolution range $(\AA ̊)$ & $32.72-1.70(1.76-1.70)^{*}$ \\
\hline Space group & P 1 \\
\hline Unit cell & $\begin{array}{l}66.0267 .2287 .67 \\
68.1068 .4383 .07\end{array}$ \\
\hline Unique reflections & $137819(13468)$ \\
\hline Multiplicity & $4.1(4.0)$ \\
\hline Completeness (\%) & $96.0(94.0)$ \\
\hline Mean I/sigma(I) & $13.2(1.7)$ \\
\hline Wilson B-factor $\left(\AA^{2}\right)$ & 25.5 \\
\hline R-merge (\%) & $0.047(0.923)$ \\
\hline R-meas (\%) & $0.054(1.066)$ \\
\hline R-pim (\%) & $0.027(0.570)$ \\
\hline CC1/2 & $0.999(0.768)$ \\
\hline R-work (\%) & $0.174(0.301)$ \\
\hline R-free (\%) & $0.196(0.325)$ \\
\hline No. of non-hydrogen atoms & 8144 \\
\hline macromolecules & 7105 \\
\hline ligands & 238 \\
\hline water & 744 \\
\hline Protein residues & 877 \\
\hline RMS(bonds) (Å) & 0.011 \\
\hline RMS(angles) ( $\left(^{\circ}\right)$ & 0.97 \\
\hline Ramachandran favored (\%) & 98.0 \\
\hline Ramachandran outliers (\%) & 0 \\
\hline Clashscore & 6.21 \\
\hline Average B-factor $\left(\AA^{2}\right)$ & 40.8 \\
\hline
\end{tabular}




\begin{tabular}{|l|l|}
\hline Macromolecules $\left(\mathbf{\AA}^{2}\right)$ & 40.2 \\
\hline Ligands $\left(\mathbf{\AA}^{\mathbf{2}}\right)$ & 33.6 \\
\hline Solvent $\left(\AA^{\mathbf{2}}\right)$ & 48.4 \\
\hline
\end{tabular}

* Statistics for the highest-resolution shell are shown in parentheses.

\section{The Binding Site of 34a at the A-B Spike}

An additional molecule (34a) is identified at the A-B spike, probably due to the excess of ligand during the crystallization setup (Figure S3).

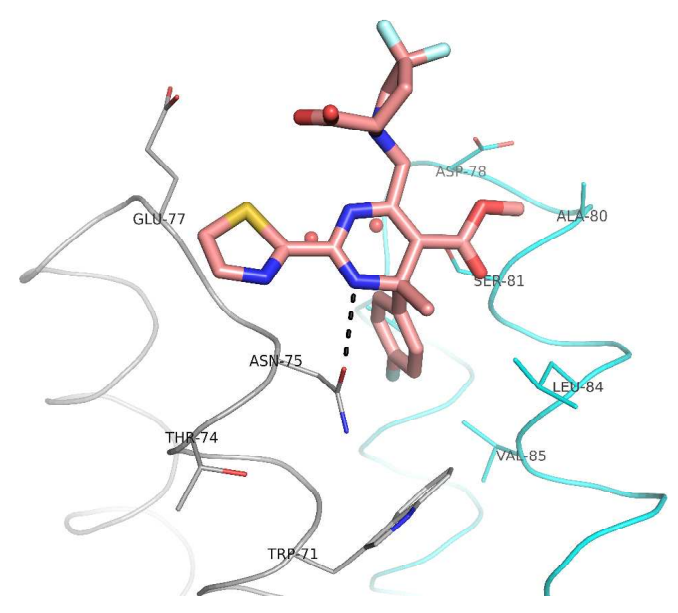

Figure S3. The secondary binding site of 34a. The compound binding pocket at A-B spike is shown. Chain A and Chain B of Y132A-34a structure are in gray and cyan colors, respectively. Compound 34a is highlighted as pink stick. Residues within $4 \AA$ radius are shown as lines. Red spheres represent water molecules in the pocket. Black dash line indicates hydrogen bond between 34a and core protein.

\section{CYP Inhibition and Plasma Protein Binding Tests}

4-Methyl HAP analogue 34a was evaluated for CYP inhibition and plasma protein binding with a TECAN Freedom EVO automation system (Tecan Group US, Inc.). A SpectraMax Plus UV plate reader was used to collect the UV spectra. The LC-MS/MS measurement was carried out with an Agilent 1200 series HPLC system (Applied Biosystems API 4000 triple quadrupole with 
TurboIonSpray interface). The mobile phase contains A: $0.1 \%$ of acetic acid in Milli-Q water and B: $0.1 \%$ acetic acid in methanol.

CYP Inhibition Assay. All incubations were carried out under conditions shown to be linear with respect to time, protein concentration and substrate concentration (all at the literature reported $K m$ values). Each sample contained $0.125 \mathrm{mg} / \mathrm{ml}$ of human liver microsome (HLM, protein content), $5 \mathrm{mM}$ of $\mathrm{MgCl}_{2}, 100 \mathrm{mM}$ of potassium phosphate buffer (pH 7.4), cocktail substrates, 34a and $2 \mathrm{mM}$ of NADPH in a final volume of $200 \mu \mathrm{L}$. And the DMSO concentration was $0.75 \% \mathrm{v} / \mathrm{v}$. Samples (except NADPH) were pre-warmed at $37^{\circ} \mathrm{C}$ for at least 10 min before NADPH was added to initiate the reaction. Incubation was terminated 30 min later by the addition of $100 \mu \mathrm{L}$ of methanol and dextrorphan $(3 \mu \mathrm{M})$ was used as an internal standard. Samples were centrifuged at $4000 \mathrm{rpm}$ for 10 min at $4{ }^{\circ} \mathrm{C}$. The supernatant from each sample was then analyzed by LC-MS/MS. Compound 34a exhibited low CYP inhibition against five major CYP enzymes (3A4, 2D6, 2C9, 2C19, 1A2) with IC $_{50}$ values $>30 \mu \mathrm{M}$.

Plasma Protein Binding Assay. The plasma protein binding assay was based on equilibrium dialysis in 96-well plates (HTDialysis, Gales Ferry, CT) with warfarin and phenobarbital used as positive controls. Pooled human and mouse plasma were purchased from Innovative Research, Inc., Southfield, MI. Sorensen's phosphate buffer (0.15M, pH 7.4) was ordered from Electron Microscopy Sciences, Hatfield, PA. At first, the dialysis membrane was activated in Milli-Q water for $1 \mathrm{~h}$ and then in $20 \%$ ethanol for $20 \mathrm{~min}$, and washed twice with Sorensen's phosphate buffer. A $2 \mu \mathrm{L}$ aliquot of 34a stock solution ( $2 \mathrm{mM}$ in DMSO) was spiked into $400 \mu \mathrm{L}$ of plasma to make a final concentration of $10 \mu \mathrm{M}$. Then $150 \mu \mathrm{L}$ of aliquots were loaded into the dialysis wells (donor) and dialyzed against 150 $\mu \mathrm{L}$ of Sorensen's phosphate buffer (receiver) in a water bath at $37^{\circ} \mathrm{C}$ for $5 \mathrm{~h}$. At the end of incubation, aliquots of plasma and buffer samples were transferred into a 96-well plate, vortex-mixed with blank and tolbutamide solution (internal control) and centrifuged before LC-MS/MS analysis. The unbound free fractions $(\mathrm{F} u)$ of $\mathbf{3 4 a}$ were determined to be $1.9 \%$ and $8.1 \%$ in human and mouse plasma, respectively.

\section{Size-Exclusion Chromatography (SEC) Study of Capsid Assembly.}


4-Methyl HAP analogue 34a was evaluated for its effects on the capsid assembly or aggregation of the $N$-terminal capsid assembly domain (Cp149), which exists as stable dimers in the buffer of $50 \mathrm{mM}$ HEPES (pH 7.5) and $150 \mathrm{mM} \mathrm{NaCl}$. The capsid assembly was initiated by mixing Cp149 with 34a and the solution was incubated at $\mathrm{rt}$ for $1 \mathrm{~h}$. The degree of Cp149 assembly was examined by size-exclusion chromatography (SEC). A high resolution column (TSKgel G3000SWXL) was mounted on an HPLC system equipped with an auto-injection module. The column was equilibrated with $50 \mathrm{mM}$ of HEPES (pH 7.5) and $150 \mathrm{mM}$ of $\mathrm{NaCl}$. The recovered protein was defined as the capsid or aggregation of Cp149 dimers that had a retention time of 5-6 min and Cp149 dimers, which had a retention time of 8-9 min. Compound 34a induced capsid assembly in a concentration dependent manner (Figure S4).

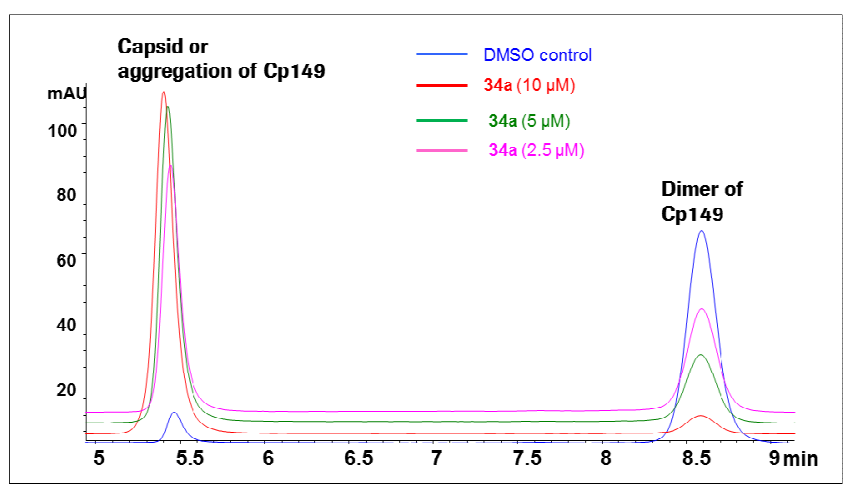

Figure S4. Compound 34a induces capsid assembly of Cp149 dimers.

\section{Electron Microscopy Study of Capsid Aggregation Induced by 34a.}

To investigate the capsid aggregation induced by 4-methyl HAP analogue 34a, the stable dimer of $N$-terminal capsid assembly domain (Cp149) was used in the transmission electron microscopy (TEM) study. A mixture of Cp149 dimers $(5 \mu \mathrm{M})$ in $500 \mathrm{mM}$ of $\mathrm{NaCl}$ solution was incubated with DMSO (used as negative control) or $10 \mu \mathrm{M}$ of 34a at $\mathrm{rt}$ for $1 \mathrm{~h}$. Samples were stored at $4{ }^{\circ} \mathrm{C}$ and shipped to Wuhan Institute of Virology for further embedding, negative staining and sections. The formation of capsid particles was observed by TEM. As shown in Figure S5, the incubation of Cp149 dimers with 34a resulted in enlarged or misassembled capsid particles instead of the normal-sized capsids formed under DMSO control. 


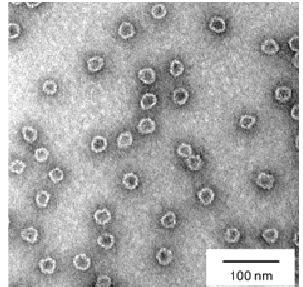

DMSO Control

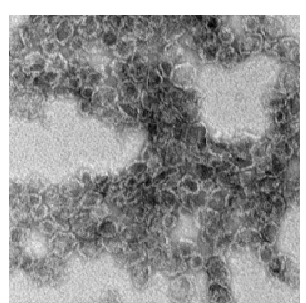

$34 a$

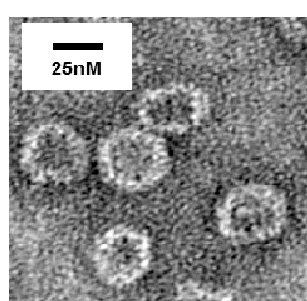

DMSO CtrI

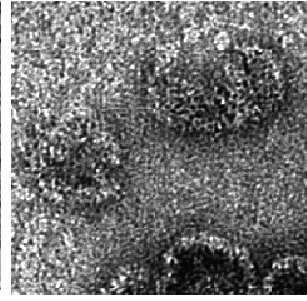

$34 a$

Figure S5. Compound 34a induces aggregation of Cp149 dimers. 